\title{
Individual Change and Cultural Process: Their Role in Virtual Community Building
}

\author{
K. Ann Renninger (Organizer and Moderator) \\ Swarthmore College, Program in Education, 500 College Ave. Swarthmore, PA 19081 \\ krennin1@swarthmore.edu \\ Wesley Shumar (Organizer and Presenter) \\ Drexel University, PSA Department, 3141 Chestnut St. Philadelphia, PA 19104 \\ Shumarw@drexel.edu \\ Linda Polin (Organizer and Presenter) \\ Pepperdine University, Graduate School of Education and Psychology, 400 Corporate Pointe \\ Culver City, CA 90230 lpolin@ @epperdine.edu \\ Mark Schlager (Presenter) \\ Center for Technology in Learning, SRI International, 333 Ravenswood Avenue, Menlo Park, CA 94025 \\ schlager@unix.sri.com \\ William S. Spitzer (Presenter) \\ New England Aquarium, Central Wharf, Boston, MA 02110-3399 \\ E-mail: bspitzer@neaq.org
}

\begin{abstract}
There are a wide variety of virtual communities, each of which offers metaphors for interaction and paths of communication. In this symposium, discussion focuses on the relation between user and the site. Short presentations of four different sites will be followed by discussion of: (a) how change might be described; (b) the constraints and possibilities inherent in a site; and (c) how the "culture" of a virtual community might be described.
\end{abstract}

Keywords: computer-mediated communication, learning communities, learning environments

\section{Introduction}

The individual and social construction of the self have been the focus of much of the literature on computermediated communication and virtual community (i.e., Cherny, 1996; Donath, 1999; Jones, 1997; Turkle 1995). There has been less emphasis on the ways in which individual users change over time and the implications of this change for understanding community design and development. Research on physical communities suggests that there is a dynamic and dialectical interplay between the development and change of individuals and the evolution and change of culture (i.e., Cole, Engeström \& Vasquez, 1997; Roth, McGinn, Woszczyna \& Boutonné, 1999). Such findings raise important questions for the internet and the virtual world: Do online communities have cultural features that transcend particular sites and do they have a similar impact on individuals? Are individual roles similar across different sites? (e.g., do leadership, learning and personal satisfaction look different or similar across different virtual communities?) As we move forward to develop online communities in a world of changing bandwidth and design possibilities, understanding the way site design interacts with individual behavior, community growth and change will become a necessity.

\section{Session Format}

This interactive symposium addresses the interplay between individual change and cultural processes as it has emerged in sites serving different functions: professional development, museum education, graduate education and internet resource center with structured activity including interaction. Examination of the relation between site design, individual change and cultural process across sites with different functions should enable articulation of agendas for research and practice that are useful to building community. Presentations will be short in order to allow for discussion. Ann Renninger will serve as moderator. She will open the session by providing an overview of 
issues implicit in discussions of the role of change and cultural practices in the growth and maintenance of virtual communities. The participants will describe the web environments with which they are involved, drawing on data specific to these sites in order to answer the following questions:

1) How might "change" in a virtual community be described?

2) What degree of constraint and possibility are inherent in the design of a site, and how does this interact with change in the community? Has this changed over time?

3) How might one think about the "culture" of a community in a virtual environment?

Discussion of these questions will then be opened to the participants and the audience in order to permit exchange of ideas about the ways our thinking with regard to culture and change can facilitate the strategies groups employ to design and sustain their online communities.

\section{Presentation Summaries}

\section{Knowledge-building in an Online Teacher Professional Development Community (Mark Schlager, Judith Fusco, and Patricia Schank SRI International)}

The concept of community of practice has become a major theme of teacher professional development (TPD) research and practice. Advocates argue that communities of practice (CoPs) can be powerful catalysts for enabling teachers to improve their practice. Three years ago, we set out to establish an on-line TPD research testbed that could scale to support thousands of teachers' professional activities while forging the kind of professional community that TPD policy researchers have found to undergird successful local school reform efforts. Our challenge was to instantiate the affordances of a CoP within the constraints of most teachers' work environment through the Internet. The result is a work in progress called TAPPED IN. In this session, we provide an overview of our on-line CoP model and the online tools, services, and social norms that we have developed to foster communitybuilding and support effective professional development strategies.

The technology underlying TI is a platform-independent, Web-enhanced, multi-user virtual environment designed to support large numbers of education professionals and TPD organizations in a single virtual place. Activities occur (in real time or asynchronously) in rooms of a virtual conference center that provide a basic set of communication mechanisms (speaking, whispering, paging, nonverbal actions) and support tools (e.g., virtual whiteboards, sharable text documents, Web page projection, transcript recorders) that enable users to be more expressive than with other types of online communication tools. Although the user experience differs from the physical world in significant ways, the TAPPED IN community is akin to CoPs or professional networks of colleagues found in the corporate world; the environment mimics the kind of office park or conference center that many corporations have established. Educators can attend activities hosted by a variety of education organizations, conduct their own on-line activities, or expand their circle of colleagues by participating in community-wide activities.

Over time, the environment has changed in several ways to adapt to the needs of its users. The most obvious development has been the migration from text-only, to Web-based user interface, and then Java-enabled as Web browsers have become more sophisticated. More subtle changes include assistance for customizing offices, virtual tape recorders, object vending machines. A parallel evolution has occurred in the capacity of our users to engage in increasingly sophisticated types of online activities without outside assistance. Members progress from curious novices, to participants, to leaders of community groups over time. We believe that this evolution has been a function of both the explosive increase in Web use among teacher in general and the capacity-building services we offer TAPPED IN members and partner organizations.

\section{The Virtual Museum: Museums and On-line Communities (William Spitzer, New England} Aquarium)

Museums and the Internet are intriguing in their similarities and differences. Both are environments for voluntary learning and exploration, rich in information resources and in human interactions. Yet, the Internet is virtual while museums are real, physical spaces. 
A number of museums have begun to find their way in the on-line environment. There is a wide range of approaches being attempted, ranging from creating on-line versions of museum collections, to using the Internet in innovative ways to extend a visitor's experience beyond the museum visit. All of these efforts are attempting to answer the question: What are the most appropriate technical and social structures needed to create a "virtual museum"?

What are effective and appropriate ways in which museums-rich in collections, information resources, and staff-can effectively engage with the world of the Internet? What is distinctive about museum-based Internet communities? How does the physical presence of a museum constrain and enlarge the range of possibilities?

This presentation will compare and contrast several examples of museum-based internet environments, addressing the notions of community and culture, as well as how these environments are changing, in response to changing needs of users, changes in museums, and changes in the Internet. Although experimentation by museums with these issues has been far from systematic, some best practices are beginning to emerge as several museums are beginning to define the nature of their virtual visitors.

\section{Symbiotic Transformation in Virtual Communities (Linda Polin, Pepperdine University)}

In 1995 Pepperdine University began offering an Ed.D. program in educational technology leadership partially via the Internet. Three years later we moved our masters program in educational technology online as well. Students enter the programs in cadres of approximately 24 people each, and proceed lock step through the coursework together. In a mandatory summer pre-session called VirtCamp (for the MA) or TechCamp (for the EdD) students spend five full days on campus to accomplish two pre-program goals: a) master the tools for learning at a distance in a networked environment, and b) establish a common team bond which serves as the foundation for participation in our online community. Students and faculty use six main tools for asynchronous and synchronous communication: a) a real-time, multi-user virtual text-based chat environment called Tapped In; b) private or small group real-time chat and instant messaging programs (ICQ or AIM); c) asynchronous public discussion forums threaded by topic, called newsgroups; d) shared multimedia hyperlinked documents, i.e., WebPages; e) subscription-based groupdistributed email programs called listservs; and f) private email correspondence. Occasionally classes fiddle with CU See Me and other video streaming programs, but generally the students don't like them and this has remained an unintegrated novelty. Faculty and students also have been known to use phone and FAX to augment online interactions.

Change in our virtual community, like change in real world communities, is best described as a transformation rather than as accumulation or acquisition. Students become different people in the practice and this translates into their "real world" workplace. The community changes too, though more slowly, by evolving the practice: tools, behaviors, and goals. As each cadre enters and moves through the program, it generates variation in the way we do our work. Each change we make, in turn, affects the way the cadre makes sense of its work as well. It is safe to say that we are evolving our practice in concert with evolutions in our identities as faculty and students, learners and teachers, working with technology in educational enterprises. In our doctoral program, by the end of the coursework (the end of the second year) approximately half the students are no longer employed in the same job description as they were upon entering the program. In the MA program, this is also true, to the extent that some students actually resign from their jobs at the end of the program.

But what of change in the community itself? As students and faculty in the program are experiencing this transformation they are also interacting with students chronologically ahead and behind them, i.e., other generations in the community. Under the watchful guidance of specific faculty, doctoral students and masters students run the VirtCamp and TechCamp for the incoming generations. The advanced doctoral students have the opportunity to teach in the online MA program as well. These moves put students on the other side of the virtual desk and allow them to be different people in the community. These moves may seem to an outsider to result in a "closed" or "inbred" community. But actually these moves open up the community by giving members access to each other, to behaviors, beliefs, and knowledge-in-use of others who are further along in the practice.

Fortunately, our online learning community is a relatively new environment, lacking the historical baggage that severely constrains higher education. We are all contributing to the conventions of online community as we re-enact the program with each new cadre. Slowly our traditions are emerging. It has taken us a while to figure out what the 
practice is that our community has formed around. During that time, the flexibility of our work community (people, tools, practices) has allowed us to make important discoveries, some of which will be offered in this presentation.

\section{The Development of a Community of Problem Solvers (Wesley Shumar, Drexel University and K. Ann Renninger, Swarthmore College)}

Using the Math Forum (forum.swarthmore.edu) as a case example, this paper addresses the way in which the internet forms the core of an intentional on-line community by promoting communication between interested parties. The Math Forum has been an NSF-funded internet resource center for math education that is in a transition to becoming self-sustaining. It also is a unique group of individuals who are committed to using computers and the internet to foster community building. This group includes the Forum staff and an ever-expanding number of teachers, students and other individuals (i.e. parents, software developers, mathematicians). Thus community building at the Math Forum is described in terms of: work with teachers, work with partners (NCTM, MAA, and so on) and work with specific projects (i.e., Ask Dr. Math) that allow teachers and students to come together and solve problems. Interestingly, however, in addition to providing the scaffold for community building, the staff also considers themselves to be part of the community.

An important part of all groups is their capacity to grow and change, responding to new problems and new needs. As a virtual community, the Math Forum has a dynamic and somewhat elusive quality-- complicating assessment and understanding of interactional processes, as well as the usage of conventional indicators to assess change. Multiple methods (ethnographic, focus groups, interview, questionnaires, experimental) have been employed to study community participation. Change has been studied at three levels of analysis across the different Math Forum services: subject characteristics (individual), mathematical and pedagogical thinking (dyadic), and cultural process (group). These data are used as the basis for addressing questions of the session.

Briefly, because the Math Forum is a dynamic community, it is constantly undergoing change. What remains constant is its approach to working with people to learn and the depth and breadth of its resources for mathematics. It changes in relation to the strength and needs of its users, including the increased demands for its services. Another critical constant is the presence of users as mentors, contributors, problem solvers, etc. Given its rich texture, the Forum is a site that provides for changing imagination about community and offers multiple opportunities for identity and leadership. Its culture, evolves in response to and through a reciprocal relation of staff and user community members.

\section{References}

Cherny, L. \& Weise E. R. (Eds.) (1996) Wired women: Gender and new realities in cyberspace. Wash.: Seal Press.

Cole, M., Engeström, Y. \& Vasquez, O. (Eds.) (1997) Mind, culture, and activity: Seminal papers from the Laboratory of Comparative Human Cognition. Cambridge; New York: Cambridge University Press, 1997.

Donath, J. (1999) Identity and deception in the virtual community. In M. A. Smith \& P. Kollack (Eds.) Communities in Cyberspace. London; New York: Routledge.

Jones, S. G. (Ed.) (1997) Virtual culture: Identity and communication in cybersociety. London; Thousand Oaks; New Delhi: Sage Publications.

Roth, W., McGinn, M. K., Woszczyna, C. \& Boutonné, S. (1999) Addressing the challenges of inquiry-based learning through technology and curriculum design. The Journal of the Learning Sciences, 8 (3+4), 293347.

Turkle, S. (1995) Life on the screen : Identity in the age of the Internet. New York : Simon \& Schuster, 1995. 